\title{
Corpus
}

Archivos virtuales de la alteridad americana

Vol. 9, No 2 | 2019

Julio / Diciembre 2019

\section{Casa poblada y buen gobierno. Oeconomía católica y servicio personal en San Miguel de Tucumán, siglo XVIII, de Romina Zamora. Buenos Aires: Prometeo, 2017. 250 páginas.}

\section{Roxana Boixadós}

\section{OpenEdition}

\section{Journals}

Electronic version

URL: http://journals.openedition.org/corpusarchivos/3330

ISSN: 1853-8037

\section{Publisher}

Diego Escolar

\section{Electronic reference}

Roxana Boixadós, «Casa poblada y buen gobierno. Oeconomía católica y servicio personal en San Miguel de Tucumán, siglo XVIII, de Romina Zamora. Buenos Aires: Prometeo, 2017. 250 páginas. », Corpus [En línea], Vol. 9, No 2 | 2019, Publicado el 26 diciembre 2019, consultado el 28 diciembre 2019. URL : http://journals.openedition.org/corpusarchivos/3330

This text was automatically generated on 28 December 2019. 


\title{
Casa poblada y buen gobierno. Oeconomía católica y servicio personal en San Miguel de Tucumán, siglo XVIII, de Romina Zamora. Buenos Aires: Prometeo, 2017. 250 páginas.
}

\author{
Roxana Boixadós
}

1 El libro de Romina Zamora es el resultado de una larga experiencia de investigación sobre diferentes problemáticas de la sociedad colonial de la jurisdicción de San Miguel de Tucumán en el siglo XVIII y traduce su profundo conocimiento de un mundo que a lo largo de años ha ido abordando desde la dimensión social, económica, política y jurídica. Traduce igualmente un significativo manejo de fuentes de archivo, una familiaridad y dominio de diversos microcosmos que ha sabido con buena pluma reconstruir, interpretar y glosar, para acerca a los lectores personajes, situaciones y problemas que permanecen guardados en los papeles antiguos.

2 No se trata sin embargo de una obra de síntesis sino de una reelaboración sustanciosa y reflexiva que hace eje en las características del modelo que imprimió duraderas lógicas de relacionamiento social, económica y de poder en la colonia: el de la casa poblada. Modelo que es parte de un legado cultural enraizado en la noción de orden oeconómico propuesto por Otto Brunner para estudiar el dominio territorial señorial en la Europa del antiguo régimen del siglo XVII y que refiere a la potestad de un señor para gobernar a quienes vivían bajo su dominio, su "casa", tanto fuera parientes como allegados y sirvientes. Tal noción constituyó una herramienta central para desvendar la cultura jurídica de antiguo régimen y sus implicaciones sobre las relaciones sociales, económicas y políticas, articuladas en torno a valores pactistas y reciprocitarios que recorren desde el orden doméstico hasta los niveles más altos de la jerarquía social y 
religiosa, tal como las investigaciones sobre el mundo rural español de la baja edad media y la temprana edad moderna han mostrado. Pero aquí la noción requiere de adaptaciones convincentemente tramadas por la autora porque estamos tratando con una sociedad colonial construida sobre la base de la dominación española sobre los pueblos nativos y donde la condición de la "servidumbre" -indígena, mestiza o esclavaestá respaldada por un orden jurídico particular y sostenida por el ejercicio de la violencia, y donde los "señores" ("amos", "patronos") que presidían estas casas (unidades socioeconómicas, microcosmos de un orden mayor) no eran otros que los descendientes de osados colonizadores sin más aristocracia que la ganada por la experiencia de la conquista misma.

3 En efecto, esta sociedad -creada a partir de la fundación de la ciudad de San Miguel en 1565 pero trasladada en 1685 a su localización actual-, nos es presentada a través de una detallada recuperación de la historicidad del escenario, la descripción de la frondosa naturaleza y sus caudalosos ríos estivales, de los actores sociales -españoles, indígenas, criollos, mestizos, esclavos- que la configuraron a lo largo de los siglos XVI y XVII. Las luchas y los conflictos de estos tiempos fueron ritmando en parte su inclusión en el engranaje económico y político de una región más vasta -la gobernación del Tucumán-en la que fue a la vez centro dinámico -de producción e intercambio mercantil- y cercana frontera a los grupos chaqueños, un problema que habrán de enfrentar en distintos momentos del siglo XVIII. Es justamente el traslado de la cuidad -y con ella todo su vecindario, su materialidad, su vida cotidiana- el punto de inflexión elegido por la autora para analizar el trasiego y la refundación del orden en un nuevo espacio, consolidando un régimen de servidumbre que persistirá más allá de la diacronía colonial.

El libro se compone de nueve capítulos; los tres primeros pueden considerarse como introductorios ya que reconstruyen pacientemente las tramas de la formación de la sociedad colonial temprana en las que tienen un papel vital la conquista de los grupos indígenas locales y su incorporación al régimen de encomienda bajo el servicio personal, tanto como la organización del trabajo bajo modalidad de conciertos y conchabos. La reconstrucción de la vida cotidiana en el mundo rural recupera las tensiones y la violencia características del mundo colonial y sus estructuras de poder, crónicas de disciplinamientos que trasuntan el sometimiento cotidiano -y las resistencias también- de los nativos que debían responder a sus encomenderos. Junto a esto, el conchabo doméstico representa un vínculo que encuadra a la población libre (indios, mestizos y castas) en relación a un señor o amo -y a su familia- ejerciendo sobre ellos protección y control, rasgos que las políticas de los Borbones tenderá a reforzar a lo largo del siglo XVIII. Como contrapunto al mundo rural, se aborda la vida urbana donde una población variopinta participaba de las instituciones de gobierno, asistía a las liturgias de la Iglesia, componía el coro de vecinos, estantes, moradores, convivientes de un creciente sector compuesto por criados, mestizos y castas. La composición de la historia local con sus escenarios y actores diversos enlaza con el debate sobre el traslado de la ciudad desde Ibatín hacia La Toma, después que la importante crecida del río del Tejar en 1678 sumara argumentos acerca de las condiciones poco benignas del clima del lugar. El nuevo emplazamiento, ubicado en la ruta del Alto Perú, prometía compensar al nuevo vecindario con beneficios económicos, factor que algunos vecinos notables supieron capitalizar durante el siglo XVIII. Interesa destacar que esta refundación supuso un traslado masivo que se consumó en un tiempo 
largo, ritmado por la construcción de nuevas casas, iglesias, acequias y calles de las que indígenas y trabajadores concertados debieron cuenta.

5 Los siguientes cuatro capítulos se abocan al análisis de las casas pobladas de la nueva ciudad. El nuevo emplazamiento es reconocido y "leído" como una cartografía social en la que el status puede identificarse por el lugar que ocupan sus viviendas y solares en torno a los espacios simbólicos de mayor prestigio: la plaza central, el cabildo, la iglesia. Las casas pobladas se organizan en torno al patrimonio y a quien detenta la autoridad de administrarlo y mejorarlo, el señor, y a su familia, secundada por la servidumbre que orbita bajo su dominio, protección y dependencia. La autora examina los cambios en la composición y la distribución de la población en el espacio urbano a través del análisis de varios censos, pleitos judiciales, protocolos notariales, entre otras fuentes, lo mismo que las dimensiones de las viviendas, su distribución interna y funcionalidad. El crecimiento de la población y sobre todo la intensa actividad mercantil que en ella tiene lugar, genera la apertura de cuartos de alquiler para tiendas, pulperías, viviendas, pequeños talleres, etc. La ciudad tenía así -lo mismo que otras muchas ciudadesespacios sociales diferenciados, el de las familias acomodadas o casas pobladas y los de la plebe (la casa plebe), signado por la marginalidad y la precariedad, y sobre los que irán a recaer los bandos de buen gobierno de la segunda mitad del siglo XVIII.

6 Los últimos dos capítulos están dedicados a examinar la dimensión política de la casa poblada y sus proyecciones en el gobierno de la ciudad a través de los vecinos que ejercieron oficios capitulares, militares y de administración real. El carácter corporativo de las instituciones de gobierno confiere a quienes los detentaban identidad social, status y privilegios en el marco de la república de españoles debiendo aspirar al bien común. Sin embargo, con correr del siglo la autora analiza las mutaciones de sentido que tal expresión fue sufriendo: desde una noción cifrada en lo colectivo hacia una más restrictiva que dejaba afuera a los sectores bajos, la plebe urbana. De nuevo es con la administración de los borbones que los controles sociales se redefinirán a partir de la aparición de los alcaldes de barrios quienes actuaban con poder de policía para evitar desmanes, combatir la ociosidad -considerada causa de "vicios" diversos-, y preservar las buenas costumbres en la ciudad y la jurisdicción observando los bandos e instrucciones de las autoridades superiores.

7 El tema de cada capítulo es presentado a través de un episodio documentado en archivo; la autora utiliza este recurso hábilmente, no solo para introducir literariamente al lector en el contexto donde discurrirán sus próximos argumentos e interpretaciones sino para hacer más presente un pasado colonial que a lo largo del libro se reconoce menos lejano. El libro trata sobre la dominación, la servidumbre, las lógicas de sometimiento social, las jerarquías impuestas, el poder de unos sobre otros y los marcos jurídicos y culturales en los que sus legitimidades descansan. Quienes atraviesan la distancia temporal del lejano siglo XVIII hasta las páginas de Casa poblada $y$ buen gobierno, cobrando vitalidad en la introducción de cada capítulo, son hombres y mujeres que experimentaron ese orden cotidiano y del que son recuperados por Romina Zamora para reponer sus lazos con el contexto en el que desplegaron sus sentidos y también con el presente. Esta estrategia recuerda -y mucho- a ciertos estilos de historia cultural o microhistoria, donde las reconstrucciones en escala pequeña permiten recrear universos domésticos, la agencia de los actores sociales y vislumbrar merced a detalladas descripciones- sus expectativas y penurias. Sin embargo, el libro supera esta clasificación en la medida en que también se advierte en su original 
problematización la matriz de la nueva historia del derecho, tal como la presentación de Bartolomé Clavero nos advierte. Es también -y sobre todo- un muy buen libro de historia colonial, de los que enseñan, motivan, inspiran y llaman a ser leídos más de una vez.

\section{AUTHOR}

\section{ROXANA BOIXADÓS}

CONICET-Universidad de Buenos Aires- Universidad Nacional de Quilmes

roxboixados@gmail.com 